Arab World English Journal (AWEJ) Volume 12. Number3 September 2021

Pp. 338-350

DOI:https://dx.doi.org/10.24093/awej/vol12no3.23

\title{
Exploring Psychotypology as an Affective factor of Cross-Linguistic Influence: Case of Algerian Multilingual Learners
}

Fatima Zohra Athmani

English Department, Faculty of Foreign Languages

University of Algiers 2, Algiers, Algeria

Corresponding Author: Fatimazohra.athmani@univ-alger2.dz

Yasmine Boukhedimi

English Department, Faculty of Foreign Languages

University of Algiers 2, Algiers, Algeria

Received: 6/30/2021

Accepted: 8/22/2021

Published:9/24/2021

\begin{abstract}
Multilingualism has established itself as a separate area of research in linguistic studies for the two last decades. Therefore, the present study aims at examining Algerian Multilingual students' perceptions of linguistic distance i.e., psychotypology, between their first Language Arabic and Second language French and third language English. It focuses on the role of psychotypology as a constraining factor of cross-linguistic influence in third language acquisition that may lead to the activation of the background languages in the production of L3 English. Therefore, the researcher used a mixed research method to explore which typological or psychotypological languages L1 Arabic or L2 French would be the source of language transfer in L3 production. Forty students participated in this study, and data was gathered through a psychotypological questionnaire. The results of a qualitative and quantitative analysis showed students perceive French as a closed language to English in most the language aspects and they used it to fill a linguistic gap in their English production. It also showed that psychotypology is a complex concept that would affect students' language choice in L3 production as well as a crucial factor in determining the source language of transfer. The findings indicated that further investigations of Psychotypology in L3 production are necessary.
\end{abstract}

Keywords: Algerian, Cross-linguistic influence multilingualism, multilingual Learners. psychotypology. third language acquisition, typology

Cite as: Athmani, F. Z., \& Boukhedimi, Y. (2021). Exploring Psychotypology as an Affective factor of Cross-Linguistic Influence: Case of Algerian Multilingual Learners. Arab World English Journal, 12 (3) 338-350. DOI: https://dx.doi.org/10.24093/awej/vol12no3.23 


\section{Introduction}

The effect of the already acquired languages in Second Language Acquisition (SLA) and third language acquisition on the language being acquired was always a controversial issue. Research depends on the relations between the two languages. The relationship between languages can be measured through measurable terms like typological comparison. Hence, it could be biased due to specific individual perceptions and beliefs about the languages where assumptions about would affect the learning process. How far, or how close the learner assumes the target language to be from his background languages can assume a positive or a negative cross-linguistic influence. Kellerman (1986) suggested that what affected transfer is not typology, but rather psychotypology - the learner's perceived distance between the first language (L1) and Second Language (L2). Kellerman also suggested that when the learner acquires a larger understanding of the target language, the estimate of the psychotypological distance will gradually change. Much of the perceived suitability of the source language structures depends on the perceived distance between the two languages (Kellerman, 1982). Since the multilingual participants in the present study have two potential source languages: Arabic and French, from which crosslinguistic influence on English might take place, psychotypology is an important aspect of consideration to the choice of the source language of transfer. Therefore, the researcher aimed at knowing students' perceptions of linguistic distance, between Arabic, French, and English that is significant in determining the source language of transfer In this concern the following research questions were formulated:

a) How do Algerian students perceive the linguistic distance between L1 Arabic, L2 French, and L3 English?

b) Which of the background languages Arabic or French is perceived closer to English?

c) Which of the background languages L1 or L2 can be the source of transfer

The main objective of this research is to know students' perception of their linguistic repertoire and how their background languages negatively influence their production in L3 English. The linguistic perception or psychotypology enables the researcher to determine which of the background languages is the source language of transfer that affect the target language production negatively.

\section{Literature Review Multilingualism}

Third Language Acquisition (TLA) has been of recent interest in the field of linguistics and language acquisition. Along with this growth of the TLA field, however, there is increasing concern over giving an accurate definition to the terms: 'multilingualism', and 'multilingual'. The concept of multilingualism has been defined from different perspectives depending on the background and ideologies and theoretical orientations of the researchers that led to the diverges in understanding the concept. For instance, the francophones used the term Plurilingualism to refer to individual multilingualism as opposed to societal multilingualism (Cenoz, 2013). Whereas some scholars used the term multilingualism to refer to both societal and individual multilingualism "Is the use of three or more languages by an individual or by a group of speakers such as the inhabitants of a particular region or a nation" (Richards \& Schmidt, 2016, p.379). In psycholinguistic studies, multilingualism is generally used to refer to individual multilingual and is defined as "speakers who use two or more languages or dialects in their everyday lives" 
(Pavlenko, 2007, p16) While a neutral definition goes as "Multilingualism is widely regarded as a natural state of humankind" (Flynn, 2016, p. 2).

Some studies have established that multilingualism is equivalent to bilingualism and can be used interchangeably (e.g., Aronin \& Singleton, 2008) and trilingual and L3 or Ln Additional Language's learners were not considered any different than bilinguals or L3 learners. at the same time, other scholars acknowledged the need to separate the two concepts (De Groot,2011). For example, Grosjean (2001) introduced a developed model of multilingual language processing of his previous monolingual and bilingual modal introduced in (1997), claiming that the latter do not adequately account for multilingual. Edward Dewaele (2007 "trilingualism is not just an extension of bilingualism" (p.221) and the "assumption that trilingualism differs from bilingualism only in as much as it represents more of the same" (p.221) is not sustainable.

Competence in the use of more than two languages by the individual raised another issue in defining multilingualism. Language proficiency may vary according to several factors such as the educational level, register, exposure, occupation, the context and it may fluctuate over time (Herdina \& Jessner, 2002). Kemp (2009), therefore, argued that "[r]esearchers need to decide on the degree of proficiency and functional capability multilingual are required to have for a language to count in their study (...). Researchers should specify what they mean by "multilingual" (p. 12). The views of multilingual proficiency vary from the maximal sphere of attaining a proficient level or a native-like speaker in all the languages and a minimal sphere of alternate words in languages of everyday use. Wei (2008) considers "anyone who can communicate in more than one language, be it active (through speaking and writing) or passive (through listening and reading)" (p. 4) to be multilingual. In the present study, the level of proficiency is not an effective factor in the investigation; hence the participants have at least three regularly used languages in their academic use in the Algerian educational context.

\section{Cross-Linguistic Influence (CLI)}

The field of research in TLA is "characterized by new areas of inquiry and methodologies" (Falk and Bardel 2010, p. 24). Yet the topic that has a central emphasis in Tl research was crosslinguistic influence a concept that has evolved and has greater attention recently. The concept was introduced by Sharwood-Smith and Kellerman (1986) as a broader term that encompasses many other aspects that explain the influence of prior linguistic knowledge and experience on the target language. The concept of CLI has often been used interchangeably with transfer with no implied differences to explain previous language influence. Generally, the term transfer commonly refers more to the L1 influence on L2 in Second Language Acquisition (SLA) research. Therefore, the term CLI appears to be more widely used in TLA studies. SharwoodSmith and Kellerman (1986) stated that CLI is more inclusive than transfer in that it refers to avoidance, borrowing, and L2 related aspects of language loss. However, the two terms are used interchangeably to designate the same phenomenon "cross-linguistic influence (which is a synonym for transfer)" (Odlin \& Yu, 2016, p. 1). Thus, such will be the same for this article to refer to the influence of prior linguistic knowledge of L1 Arabic and L2 French in L3 English. Williams and Hammarberg (1998) postulated that "L1 and L2 may play essentially different roles in L3 acquisition" (p. 303). 
Researchers such as Garcia-Mayo (2012), Rothman and Amaro (2010) view TLA as an opportunity to re-address recurrent questions in SLA, where new theoretical insights will be used, and new definitions will limit the scope. Several definitions have been given to the concept of CLI, Odlin (1989), for instance, defined it as "the influencing resulting from similarities and differences between the target language and any other language that has been previously (and perhaps imperfectly) acquired" (p. 27). Sharwwod Smith and Kellerman (1994) "it also means the influence of any "other tongue known to the learner on that target language" (italic in the original) (p. 198). "The term CLI seeks to explain how and under what conditions prior linguistic knowledge influences the production, comprehension, and development of a target language" (De Angelis, 2007, p19.

CLI research has also tried to explain how the mind operates when several languages are involved, and how the mind acquires, treats, stores, organizes and uses all the linguistic information that language learners possess (De Angelis, 2007). More recently, theoretical models that account for the appearance of language transfer have been developed aiming at explaining the interaction, activation, and inhibition of languages in the brain. It seeks to analyse how certain languages are activated over another and interfere in the use of another language to become the dominant supplier of linguistic luck or language inadequacies in the production of L3.

Some factors were acknowledged in the literature as constraining factors of CLI. The most extensive and structured description of the affective factors of the CLI is the one presented by Jarvis and Pavlenko (2008). They classified the variables that have been established in the literature into five groups. 1- the linguistic and psycholinguistic factors which include factors such as recency, language similarity, frequency, ..etc. 2-cognitive attention and developmental factors like language awareness, cognitive language ability. 3- factors related to cumulative language experience and knowledge such as age, length, language exposure. 4-factors related to the learning environment. 5- factors related to language use.

In the studies of CLI greater attention was given to the first category in Jarvis and Pavlenko (2008). Recent studies of CLI have given greater attention to the linguistic and psycholinguistic factors as major constraining factors of CLI. The linguistic and psycholinguistic factors refer to the different ways in which CLI is affected due to source and target language Aspects including language distance (Psychotypology), recency of use and L2 status. The present paper is only interested in the factor of language distance or Psychotypology as an effective factor in L3 English production of Algerians L1 Arabic and L2 French.

\section{Psychotypology}

Psychotypology refers to the assumed typological distance between languages. It is usually related to the learner's understanding of structural similarities and differences between two or more languages. It is defined as "the learner's perception of typological distance between languages $(. .$.$) which is the individual assessment of the degree of relationship between particular$ structures and words of L1 and L2" (Otwinowska, 2016, p. 103). The psychotypology generally comes from the learners' metalinguistic awareness in discovering certain structures of a particular language are similar or not to another one. Kellerman (1978) refers to the perception of the second language and distance from the first language as psychotypology. According to 
Kellerman (1978), transferability depends on the perceived distance between the first language and the second language and the structural organisation of the learner's first language.

Language distance can be regarded as linguistic, meaning the actual degree of difference between the languages, or as psycholinguistic, meaning the learners' assumption of the degree of difference (Ellis, 1994). Jarvis and Pavlenko (2008) highlighted the importance of distinguishing between what is objective and what is subjective with concerning similarity between languages. They mentioned that typology or the objective similarity between languages is referred to as the degree of congruence between them, while psychotypology or subjective similarity refers to the degree of congruence the learner perceives there to be.

Language similarity is seen as the main factor in language transfer both in SLA and in TLA studies, Odlin (1989) identified language distance as a factor that affects transfer and mentioned: "an objective estimation of language distance can sometimes be misleading about the likelihood of transfer: in some cases, the subjective estimation of distance by learners can override an objective measure" (p. 142, emphasis in the original). Subjective psychotypology determines the degree to which learners rely on different background languages when learning or producing the target language (Jarvis \& Pavlenko, 2008). Ellis (1994) explains the difference between subjective and objective similarity is that the objective similarity of languages can't be changed over time whereas, subjective similarity may change over time with increased exposure, use and proficiency in the target language. Ellis (1994) explained the difference between subjective and objective similarity of languages where the former refers to languages that can't be changed over time whereas the latter may change over time due to the increased exposure, use, and proficiency in the target language. A further distinction provided by Jarvis and Pavlenko (2008) is perceived versus assumed similarity between languages. While perceived similarity refers to a learner's judgment that "a form, structure, meaning, function or pattern (...) in the input of the recipient language is similar to a corresponding feature in the source language", assumed similarity, by contrast, is a learner's "hypothesis that a form, structure, meaning, function or pattern that exists in the source language has a counterpart in the recipient language, regardless of whether the L2 user has yet encountered anything like it in the recipient language" (p. 179). Falk and Bardel (2010) also offered a distinction between the subjective and objective similarity of languages. They proposed the term language 'language relatedness' to indicate a genetic relationship between languages and the term 'psychotypology' to refer to learners' subjective perception of the relative similarity between languages in their repertoire as it is originally introduced by Kellerman (1978).

The concept of psychotypology has been recently reintroduced by Rothman $(2010,2011$, 2015). In his proposed modal 'the typological primacy modal', which argues that the perceived language distance between languages has a great effect on the choice of the source language of transfer i.e. the perceived proximity between L3 and L1 or L2 is the main determinant of CLI. Therefore, this paper seeks to identify which of the prior languages L1 Arabic or L2 French is the proximate language to L3 English and which of these languages is the source language of transfer in their L3 English production. Very often, students' perceive more linguistic proximity between an L2and L3, which has come to be known as the foreign language effect (Meisel, 1983) or L2 factor (Williams \& Hammarberg, 1998). 


\section{Methods}

This research employed a mixed research method with a descriptive approach. In this study, the researcher first explored the linguistic background of the participants to ensure their multilinguality then analysed their linguistic perceptions of languages.

\section{Participants}

The selected sample included 40 students, undergraduate first-year students, at the high school of fine arts in Algiers -Algeria- during the academic year 2020-2021 the sample was conveniently selected, it includes both males and females. Their ages ranged between 17 and 19 years old. Age is considered as an influential factor in TLA and CLI studies, however, this study is not examined as an effective factor of CLI. The participants received the English language course once a week for three hours by an EFL teacher. The sample is considered as a nonhomogeneous group in terms of language exposure, use or proficiency because controlling all these aspects is an extremely hard and complex task (Aronin \& Singleton, 2012)).

\section{Research Instruments}

The current research encompasses one main research tool to answer the research questions of this study. The questionnaire was submitted to the students in the classroom to analyse their linguistic perceptions and psychotypologies of their previous languages.

\section{The Questionnaire}

A semi-structured questionnaire has been submitted to the students in the classroom. It took 15 to 20 minutes to answer the questionnaire. It contains items that aimed to know about the learners' background, language experience, language use preferences, frequency of use of each language and exposure as well as items about psychotypologies and how they subjectively perceive language distance among the three languages. The questionnaire attempts to cover most of the background knowledge factors mentioned in the literature as affective factors of language transfer.

\section{Research Procedures}

The study took place at the beginning of the second semester in 2021 and it took two weeks. During that period, students received instruction in writing in the English language. The questionnaire was first piloted before being submitted to the students to assess the comprehension and understanding of the items and make any necessary changes. The piloting was conducted with eight students from another group within the same school. The questionnaire was comprehensible and needs no modifications. The week after piloting the study the researcher submitted the questionnaire to the students in the classroom at the beginning of the session, it took 15 to 20 minutes. The teachers read first the questionnaire and asked the students if they did not understand any question. The teacher clarified some technical words that were ambiguous for the students. Later, they give it to the teacher.

\section{Results}

\section{Results of the questionnaire}

As it is mentioned before the students' age ranged from 17 to 19 years old. In response to the languages knowing all the students share the same languages, Arabic both Modern standard Arabic and Algerian Arabic (hence, Algerian Arabic will be considered as a low variety of the 
MSA in this paper), French as a second language and English as a third language. Most of the students rate themselves as proficient in Arabic and advanced in French whereas they claimed they have an intermediate level in English, only five students claimed that they have an advanced level in English.

In language use, 25 students claimed that they find themselves using French rather than Arabic whereas, 12 students find Arabic as the most identifiable language that represents them and nine students consider English as the more suitable language for them. The participants reported that they find French as the most prestigious language among the language they acquired.

In the item of which language, they express themselves better, responses differ between Arabic, French and English and also by mixing all these languages like Arabic with French or Arabic with English and even switching between the three of them i.e., Arabic, French, and English. However, the majority of the students mentioned that they find MSA as a stressful language in expressing their feelings and emotions or anxiety.

Concerning the language use and exposure to the three languages students stated that they have more exposure to French and Arabic than in English in academic contexts hence in their daily lives they have exposure to all the languages.

The most important part of the questionnaire is the students' perception of language distance. Students perceive that French is typologically closer to English than to Arabic in morphology and grammar with some distinctions on phonology while it shares only some borrowed words with the Arabic language. They perceive Arabic as a linguistically distant language with different morphology, grammar, phonetics and vocabulary. They also reported that in some cases they use French words to complete a vocabulary gap in their production of L 3 English that sometimes succeed and sometimes not.

The following tables will illustrate more findings of the study that represent their subjective perceptions of linguistic distance.

Table 1. Proficiency in Arabic

\begin{tabular}{|c|c|c|c|c|c|}
\hline & & Frequency & Percent & Valid Percent & Cumulative Percent \\
\hline \multirow{4}{*}{$\overline{\text { Valid }}$} & 3 & 5 & 12,5 & 12,5 & 12,5 \\
\hline & 4 & 14 & 35,0 & 35,0 & 47,5 \\
\hline & 5 & 21 & 52,5 & 52,5 & 100,0 \\
\hline & Total & 40 & 100,0 & 100,0 & \\
\hline
\end{tabular}

Table2. Proficiency in French

\begin{tabular}{llllll} 
& & Frequency & Percent & Valid Percent & Cumulative Percent \\
\hline Valid & 3 & 2 & 5,0 & 5,0 & 5,0 \\
\cline { 2 - 6 } & 4 & 23 & 57,5 & 57,5 & 62,5 \\
\cline { 2 - 6 } & 5 & 15 & 37,5 & 37,5 & 100,0 \\
\hline
\end{tabular}


Arab World English Journal (AWEJ) Volume 12. Number 3. September 2021

Exploring Psychotypology as an Affective factor of Cross-Linguistic

Athmani \& Boukhedimi

Table 3: Proficiency in English

\begin{tabular}{llllll} 
& & Frequency & Percent & Valid Percent & Cumulative Percent \\
\hline Valid & 2 & 1 & 2,5 & 2,5 & 2,5 \\
\cline { 2 - 6 } & 3 & 17 & 42,5 & 42,5 & 45,0 \\
\cline { 2 - 6 } & 4 & 16 & 40,0 & 40,0 & 85,0 \\
\cline { 2 - 5 } & 5 & 6 & 15,0 & 15,0 & 100,0 \\
\hline
\end{tabular}

In language proficiency, students were asked to rate themselves on a scale ranging from 1 to 5 points. $58 \%$ reported a high proficiency level in French and 53\% a high proficiency level in Arabic while $40 \%$ have a high level in English.

Table 4: The Most used Languages $\backslash$

\begin{tabular}{llllll} 
& & Frequency & Percent & Valid Percent & Cumulative Percent \\
\hline \multirow{5}{*}{ Valid } & Arabic & 26 & 65,0 & 65,0 & 65,0 \\
\cline { 2 - 5 } & French & 14 & 35,0 & 35,0 & 100,0 \\
\cline { 2 - 5 } & Total & 40 & 100,0 & 100,0 & \\
\hline
\end{tabular}

Table (4) elicits that the most used Language is Arabic in which $65 \%$ of the participants used their L1 Arabic and 35\% of them use more their L2 French while no one mentioned English as a used language.

Table 5: Languages closer to English

\begin{tabular}{llllll} 
& & Frequency & Percent & Valid Percent & Cumulative Percent \\
\hline Valid & French & 31 & 77,5 & 77,5 & 77,5 \\
\cline { 2 - 5 } & non & 9 & 22,5 & 22,5 & 100,0 \\
\cline { 2 - 5 } & Total & 40 & 100,0 & 100,0 & \\
\hline
\end{tabular}

Participants perceived that their L2 is closer to L3 English and 23\% claimed that none of their previous languages is closed to English.

\section{Discussion}

One aspect is evident from the discussion of this paper. The items of the questionnaire were built with one idea behind that is arguably the same: to explore the perceived linguistic distance between L1 Arabic and L2 French with L3 English. Participants answers show the complexity of the linguistic distance perception which will affect their production in L3. The results reflect the assumption that there are two separate concepts typology and psychotypology (Rothman and Amaro2010). Participants report that there is a typological difference between L1 Arabic and L3 English because they are genetically not related languages however, they have a subjective assumption that L2 French are distant, but they share similarities in language aspects such as Grammar, morphology, Vocabulary...etc. Kellerman (1979) Highlighted that some categories of items can be specific though close to TL. In the present study, students perceive French as a closed language to French where they can sometimes adopt items from and used them in English. 
Results show a controversy between what the participants perceive and what they implement in their learning process of L3 i.e., they report distance between L1, L2 and L3 hence they rely on their previous languages to fill a linguistic gap their production difficulties or inadequacies in both cognitive and production processes as it was mentioned in the questionnaire. it confirms Kellerman's formulation that "Actual learning experience will thus tend to affect perceptions of distance which may have originated from 'folk linguistics'. Thus, experience affects the provisional typology the learner is building up." (Kellerman, 1979, p. 40) In other words, typological proximity between French L2 and English L3 ensures cross-linguistic similarities in many subsystems that can facilitate the learners' production while in the long term, lead students to assume false similarities (or differences) that, objectively, do not exist.

The results show that psychotypology have a significant effect on the source language of transfer that participants judgement of language similarity will affect their choice of language in the production of L3 "if the learner believes that there could be a relationship between NL and TL at a given point, he may well transfer" (Kellerman, 1977, p. 93). Conversely, learners will avoid transfer, if they do not perceive any similarity between the previous languages and the target language. Otwinowska (2016) states that the mere perception of similarity between typologically distant languages can lead to a large number of errors since this influence would be stronger than that of objective interlinguistic similarity and a number of studies have demonstrated that typological judgement does affect learners' transfer behaviour (Cenoz, 2001; Lindqvist \& Bardel, 2014; Ringbom, 1986, 1987, 2001, 2007).

Psychotypology is a highly complex phenomenon, since the perception of linguistic distance is subject to change over time. For example, "it may be that a learner begins learning a language with the expectation of great similarity, only to find that there are more differences than originally anticipated" (Gass, Behney \& Plonsky, 2013, p.152). As Otwinowska (2016) points out, "lower levels of proficiency in L2 and L3 allow only for limited crosslanguage activation in language production" (p.108).

\section{Conclusion}

The main aim of this study was to explore students 'linguistic perceptions and psychotypologies as a constraining factor of CLI in multilingual studies. As we have mentioned above the descriptive statistical analysis of the Questionnaire showed the complexity of the psychotypology concept. Findings indicate that psychotypology have a significant effect on the source language of transfer in third language acquisition. As a conclusion of this research, though, psychotypology appear to have strong predictive power in determining the source of transfer, language closeness may play an important role in the choice of the source language of transfer. Hence the combination of the L2 status and psychotypology have a decisive factor in determining the amount of transfer in language production. Finally, the distinction between the two terms psychotypology and typology should be set clearly and it is necessary to measure learners' perceptions of their background languages because finding transfer from a less typological language doesn't mean that psychotypology didn't intervene in the production process.

Finally, the present study would benefit from further research on the relation between Psychotypologies or the subjective assumption between languages and the linguistic transfer in 
L3 production that will enable to examine which of the perceived languages is the source language of transfer in third language acquisition.

\section{About the Authors:}

Fatima Zohra Athmani : A PhD student, option Applied Linguistics and TEFL at the department of English at the University of Algiers -2- Algeria. She had her Masters degree in 2016 in the field of Didactics of foreign languages and cultures. https://orcid.org/0000-00022409-3905

Dr. Yasmine Boukhedimi: A University teacher at the University of Algiers -2- at the Department of English. She had her Doctorate in 2009 in the field of linguistics and didactics entitled "An exploratory study of knowledge and achievement in the English degree students at the University of Algiers with focus on literacy skills"

\section{References}

Aronin, L., \& Singleton, D. (2008). The complexity of multilingual contact and. Conversarii. Studi Linguistici, 33-47.

Aronin, L., \& Singleton, D. (2012). Multilingualism. Philadelphia: John Benjamins Publishing Company.

Cenoz, G. (2001). The Effect of Linguistic Distance, L2 Status and Age on Cross-linguistic Influence in Third Language Acquisition. In B. H. In J. Cenoz, Cross-Linguistic Influence in Third Language Acquisition: Psycholinguistic Perspective. Clevedon: Multilingual Matters.

Cenoz, J. (2013). Defining Multilingualism. Annual Review of Applied Linguistics, 33, 3-18.

De Angelis, G. (2007). Third or Additional Language Acquisition. Clevedon: Multilingual Matters.

De Groot, A. M. (2011). Language and cognition in bilinguals and multilinguals:An introduction. . New York: NY: Psychology Press.

Edwards, M., \& Dewaele, J.-M. (2007). Trilingual conversations: a window into multicompetence. . International Journal of Bilingualism 11 (2), 221-242.

Ellis, R. (1994). The study of second language acquisition. Oxford: Oxford University Press.

Falk, Y., \& Bardel, C. . (2010). The study of the role of the background languages in third language acquisition. International Review of Applied Linguistics in Language Teaching 48(2-3), 185-219.

Flynn, S. (1-3 September ). what do we mean by 'Development' in multilingual language acquisition: where do we start, where do we end how do we get there? 10th international conference on Third Language Acquisition and Multilingualism, . University of Vienna .

García-Mayo, M. d. (2012). Cognitive approaches to L3 acquisition. International Journal of English Studies, 12(1), 129-146.

Gass, S., Behney, J., \& Plonsky, L. . (2013). Second Language Acquisition: An Introductory Course. New York: Routledge.

Grosjean, F. (2001). The bilingual's language modes. In I. J. (Ed.), One Mind,Two Languages: Bilingual Language Processing (pp. 1-22). Oxford:: Blackwell.

Herdina ,P and Jessner ,U . (2002). A dynamic Model of Multilingualism. Perspectives of change in Psycholinguistics . Clevedon, UK: Multilingual Matters . 
Jarvis, S., \& Pavlenko, A. (2008). Crosslinguistic Influence in Language and Cognition. New York: Routledge.

Kellerman, E. (1977). Towards a characterization of the strategy of transfer in second language acquisition. I.S.B., 2.1, 58-146.

Kellerman, E. (1978). Giving learners a break: Native language intuitions as a source of predictions about transferability. working paper on bilingualism, 15, 59-92.

Kellerman, E. (1979). Transfer and Non-Transfer: Where We Are Now. Studies in Second Language Acquisition 2(1), 37-57.

Kellerman, E. (1982). Predicting transferability from semantic space: An investigation of translation preferences for a polysemous word. Studia Anglica Posnaniensa, 197-219.

Kellerman, E. (1982). Predicting Transferability from semantic space: An investigation of translation preferences for a polysemous word . studia Anglica Posnaniensia, 1979-219.

Kellerman, E. (1986). An Eye for an Eye: Crosslinguistic Constraints on the Development of the L2 Lexicon. In K. \&. (Eds.), Crosslinguistic Influence in Second Language Acquisition (pp. 35-48). Oxford: Pergamon Press.

Kellerman, E., \& Sharwood Smith, M. . (1986). Crosslinguistic Influence in Second Language Acquisition. Oxford: Pergamon Press.

Kemp, C. (2009). Defining multilingualism. In In Exploration of Multilingualism :Development of research on L3, multilingualism and multiple language acquisition (pp. 11-26). Amsterdam: John Benjamins.

Lindqvist, C. \&. (2014). Exploring the impact of the proficiency and typology factors: two cases of multilingual learners' L3 Learning. In I. M. (Eds.), Essential topics in applied linguistics and multilingualism. Studies in honor of David Singleton (pp. 253-266). Heidelberg: : Springer.

Odlin, T. (1989). Language transfer: cross-linguistic influence in language learning . Cambridge: Cambridge University Press.

Odlin, T., \& Yu, L. . (2016). Introduction. In I. L. (Eds.), New Perspectives on Transfer in Second Language Learning (pp. 1-16). Bristol: Multilingual Matters.

Otwinowska, A. (2016). Cognate Vocabulary in Language Acquisition and Use.Attitudes, Awareness, Activation. Bristol: Multilingual Matters.

Pavlenko, A. (2007). Globalization, gender, and multilingualism. In Gender studies and Foreign language Teaching (pp. 15-30). Tubingen: Narr, : (Eds), In Laurenz Volkmann \& Helene Decke-Cornill.

Pavlenko, A., \& Driagina, V. . (2007). Russian emotion vocabulary in American learners' narratives. Modern Language Journal, 213-234.

Rothman, J., \& Cabrelli Amaro, J. (2010). What variables condition syntactic transfer? A look at the 3 initital state. In J. \&. Rothman, Second Language Research (pp. 198-218).

Sharwood Smith, M. (1994). Second Language Learning: Theoretical Foundations. London : Longman.

Wei, L. (2008). Research perspectives on bilingualism and multilingualism. In \&. M. In L. Wei, The Blackwell Handbook of Research Methods on Bilingualism and Multilingualism (pp. 3-17). Oxford, UK: Blackwell.

Williams, S., \& Hammarberg, B. (1998). Language switches in L3 production: Implications for a polyglot speaking model. Applied Linguistics, 19(3), 295-333. 
Arab World English Journal (AWEJ) Volume 12. Number 3. September 2021

Exploring Psychotypology as an Affective factor of Cross-Linguistic

Athmani \& Boukhedimi

\section{Appendix: Students' Results of Psychotypology Questionnaire}

Table 6. Which language is closer to English in grammar

\begin{tabular}{llllll} 
& & Frequency & Percent & Valid Percent & Cumulative Percent \\
\hline Valid & French & 29 & 72,5 & 72,5 & 72,5 \\
\cline { 2 - 5 } & Non & 11 & 27,5 & 27,5 & 100,0 \\
\hline & Total & 40 & 100,0 & 100,0 & \\
\hline
\end{tabular}

Table7: Which language is closer to English in Phonetics

\begin{tabular}{|c|c|c|c|c|c|}
\hline & & Frequency & Percent & Valid Percent & Cumulative Percent \\
\hline Valid & Non & 40 & 100,0 & 100,0 & 100,0 \\
\hline
\end{tabular}

Table 8. Which language is closer to English in vocabulary

\begin{tabular}{|c|c|c|c|c|c|}
\hline & & Frequency & Percent & Valid Percent & Cumulative Percent \\
\hline \multirow[t]{3}{*}{ Valid } & French & 22 & 55,0 & 55,0 & 55,0 \\
\hline & Non & 18 & 45,0 & 45,0 & 100,0 \\
\hline & Total & 40 & 100,0 & 100,0 & \\
\hline
\end{tabular}

Table 9. Which language is closer to English in morphology

\begin{tabular}{|c|c|c|c|c|c|}
\hline & & Frequency & Percent & Valid Percent & Cumulative Percent \\
\hline$\overline{\text { Valid }}$ & French & 40 & 100,0 & 100,0 & 100,0 \\
\hline
\end{tabular}

Table 10. Which language you rely on in writing in English

\begin{tabular}{llllll} 
& & Frequency & Percent & Valid Percent & Cumulative Percent \\
\hline Valid & Arabic & 13 & 32,5 & 32,5 & 32,5 \\
\cline { 2 - 6 } & French & 26 & 65,0 & 65,0 & 97,5 \\
\cline { 2 - 5 } & Non & 1 & 2,5 & 2,5 & 100,0 \\
\hline
\end{tabular}

Table 11: Which language you think on it in your writing process

\begin{tabular}{llllll} 
& & Frequency & Percent & Valid Percent & Cumulative Percent \\
\hline Valid & Arabic & 23 & 57,5 & 57,5 & 57,5 \\
\cline { 2 - 5 } & French & 17 & 42,5 & 42,5 & 100,0 \\
\cline { 2 - 5 } & Total & 40 & 100,0 & 100,0 & \\
\hline
\end{tabular}

Table 12. Which language you used to explain a new word in English

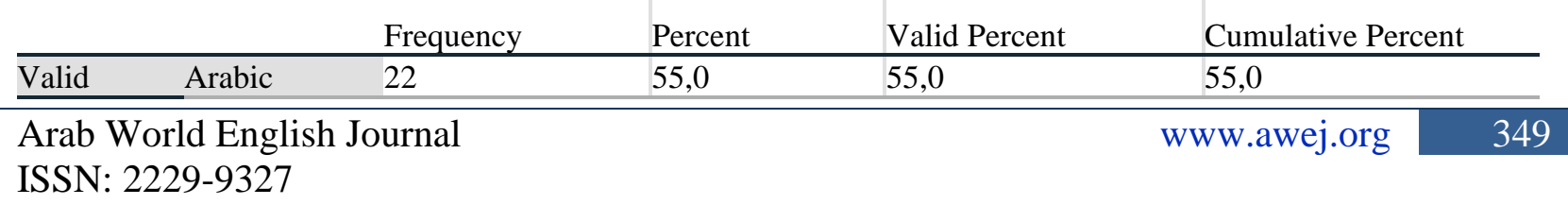


Arab World English Journal (AWEJ) Volume 12. Number 3. September 2021

Exploring Psychotypology as an Affective factor of Cross-Linguistic

Athmani \& Boukhedimi

\begin{tabular}{ll|l|l|l}
\hline French & 18 & 45,0 & 45,0 & 100,0 \\
\hline Total & 40 & 100,0 & 100,0 & \\
\hline
\end{tabular}

